\title{
The Regulation of the Alkali Consumption \\ in the Process of Direct Nickelreduction \\ from Sulphide Compounds
}

Vladimir S. Chekushin ${ }^{\mathrm{a}}$, Natalya V. Oleynikova ${ }^{* b}$ and Aleksandr V. Dontsov ${ }^{b}$ ${ }^{a}$ Krasnoyarsk Institute of Railway Engineers Branch of Irkutsk State Transport University 89 Ketshoveli Str., Krasnoyarsk, 660028, Russia ${ }^{b}$ Siberian Federal University 79 Svobodny, Krasnoyarsk, 660041, Russia

Received 11.03.2018, received in revised form 15.05.2018, accepted 27.08.2018

The possibility of reducing the chemical losses of alkali during the reduction of nickel directly from the sulfide compounds that form part of the nickel concentrate of converter matte separation is considered. It was proved that at temperatures of $350-700{ }^{\circ} \mathrm{C}$ the disproportionation of elemental sulfur in an alkaline medium is accompanied by the associationof sulfide and elemental sulfur to give the compound $\mathrm{Na}_{2} \mathrm{~S}_{n}$, (where $n=1 \div 4$ ). Titrimetric, gravimetric, $x$-ray spectral and $x$-ray phase analysis methods were used for the work.

Keywords: nickel sulfide, the metal nickel.

Citation: Chekushin V.S., Oleynikova N.V., Dontsov A.V. The regulation of the alkali consumption in the process of direct nickelreduction from sulphide compounds, J. Sib. Fed. Univ. Chem., 2018, 11(3), 333-346. DOI: 10.17516/1998-2836-0080.

(c) Siberian Federal University. All rights reserved

* Corresponding author E-mail address: aurumntc@gmail.com 


\title{
Регулирование расхода щелочи
}

\section{в процессе прямого восстановления никеля \\ из сульфидных соединений}

\author{
В.С. Чекушин ${ }^{\mathrm{a}}$ Н.В. Олейникова ${ }^{\mathbf{0}}$, А.В. Донцов ${ }^{\sigma}$ \\ ${ }^{a}$ Красноярский институт железнодорожного транспорта \\ Россия, 660028, Красноярск, ул. Ладо Кеиховели, 89 \\ ${ }^{6}$ Сибирский федеральный университет \\ Россия, 660041, Красноярск, пр. Свободный, 79
}

Рассмотрена возможность снижения химических потерь щелочи при восстановлении никеля непосредственно из сульфидных соединений, входящих в состав никелевого конщентрата разделения файнштейна. Доказано, что в условиях температур 350-700 ${ }^{\circ} \mathrm{C}$ реакции диспропориионирования элементной серы в щелочной среде сопровождаются ассочиацией сульфидной и элементной серы с получением соединения $\mathrm{Na}_{2} S_{n}$, (2де $\left.n=1-4\right)$. B работе использовань титриметрический, гравиметрический, рентгеноспектральньій и рентгенофазовый методы анализа.

Ключевые слова: сульфид никеля, металлический никель.

\section{Введение}

Процесс переработки обогащенных никелевых материалов, например сульфидных концентратов разделения файнштейна (НКРФ), представлен переделами окислительного обжига с накапливанием оксидов никеля и последующей металлизацией никеля в условиях восстановительных обжига и плавки. В целом, технология характеризуется существенными совокупными затратами, растянутостью во времени, значительными механическими потерями металла [1]. Альтернативой существующему может являться разработанный в последние годы процесс восстановления никеля непосредственно из сульфидных соединений собственной сульфидной серой в двухфазной системе, представленной дисперсным НКРФ и расплавом щелочи при температуре $\sim 700{ }^{\circ} \mathrm{C}$, обеспечивающий глубокую металлизацию никеля $[2,3]$. Получение металлической фазы непосредственно из сульфидных соединений сопровождается окислительно-восстановительным взаимодействием в условиях внутреннего электролиза и диспропорционирования образовавшейся элементной серы в щелочной среде. Суммарная реакция описывается уравнением

$$
2 \mathrm{Ni}_{3} \mathrm{~S}_{2}+8 \mathrm{NaOH} \rightarrow 6 \mathrm{Ni}^{0}+3 \mathrm{Na}_{2} \mathrm{~S}+\mathrm{Na}_{2} \mathrm{SO}_{4}+4 \mathrm{H}_{2} \mathrm{O} .
$$

Термодинамическими исследованиями установлена возможность получения металлического никеля из сульфидных соединений начиная с температуры $520^{\circ} \mathrm{C}$ [2]. Экспериментально подтверждено, что скорость процесса восстановления в интервале температур $450-700{ }^{\circ} \mathrm{C}$ с участием сульфидов различного состава возрастает в последовательности $\mathrm{Ni}_{3} \mathrm{~S}_{2} \rightarrow \mathrm{NiS} \rightarrow \mathrm{NiS}_{2}$. (В составе НКРФ преобладающим является $\mathrm{Ni}_{3} \mathrm{~S}_{2}$.)

$$
-334-
$$


Химические потери щелочи вследствие реализации мольного отношения $\mathrm{NaOH}: \mathrm{S}$, равного 2 (реакция (2), табл. 1), составляют 2.5 вес. ед. $\mathrm{NaOH}$ на 1 вес. ед. серы. В расчете на $26 \%$ серы в НКРФ химические потери щелочи составляют $65 \%$ [4].

Установлено, что при температуре $700^{\circ} \mathrm{C}$ восстановительные процессы отличаются скоротечностью и завершаются через 10-12 мин перемешивания сульфидного материала и расплава щелочи при весовом отношении щелочь : концентрат, равном 3. Уменьшение указанного отношения связано с закономерным снижением эффективности металлизации, что обусловлено возрастанием вязкости твердожидкой системы. В указанных условиях металлизация никеля сопровождается существенным уменьшением содержания в плаве $\mathrm{NaOH}$ и накапливанием сульфида и сульфата натрия $\left(\mathrm{Na}_{2} \mathrm{~S}\right.$ и $\left.\mathrm{Na}_{2} \mathrm{SO}_{4}\right)$.

Целью настоящих исследований восстановления никеля из сульфидных соединений в щелочной среде является снижение химических потерь щелочи. Основные пути решения поставленной задачи связаны с изменением химизма диспропорционирования серы:

- через накапливание в щелочном плаве в качестве одного из серосодержащих продуктов, соединений с участием $\mathrm{S}^{7+}, \mathrm{S}^{6+}, \mathrm{S}^{4+}, \mathrm{S}^{3+}, \mathrm{S}^{2+}$, координированных кислородными анионами;

- через накапливание в щелочной среде полисульфидных соединений с различной степенью ассоциации $\mathrm{Na}_{2} \mathrm{~S} \cdot \mathrm{S}_{(\mathrm{n}-1)}^{0}$.

\section{Экспериментальная часть}

Оценку термодинамической вероятности протекания процессов окисления серы и ассоциации $\mathrm{S}^{2-}-\mathrm{S}^{0}$ выполняли с привлечением банка данных, сконцентрированных в [5-8] по разработанной программе [9].

Экспериментальные исследования проводили с НКРФ, в состав которого входит (по данным спектрального анализа), \%: $70.07 \mathrm{Ni}$ и $26.3 \mathrm{~S}$. Использовались методика и оборудование, приведенные в ряде работ, например $[3,4,9]$. Для контроля температурного режима применяли термопару ХА и авторегулятор Минитерм 400.31 (погрешность измерения сигнала $\pm 0,3 \%$, разрешающая способность измерения сигнала не хуже $0.25^{\circ} \mathrm{C}$ ).

Элементный анализ состава осадков проводили рентгеноспектральным методом на рентгенофлоуресцентном спектрометре последовательного действия VRA-30.

Фазовый состав твердых продуктов исследовали на спектрометре Shimadzu XRD-6000 (излучение $\mathrm{CuKa}$, монохроматор) в следующем режиме: диапазон от 5 до $70^{\circ}$ по шкале $2 \theta$, с шагом $0,03^{\circ}$, скоростью сканирования 1,5 град/мин. Предварительно истертую пробу запрессовывали вручную в стандартную кювету из кварцевого стекла.

Рентгенофазовый анализ выполнен по программе ИПС РФА [10] с использованием БД рентгенофазовых стандартов минералов PDF2 для идентификации фаз и количественного РФА (КРФА) по мультирефлексному методу «корундовых чисел» $[11,12]$. Корундовые числа фаз (Imax/Icor) служат для приведения интенсивности (I) линий рентгенофазовых стандартов к общему масштабу (интенсивности корунда) и присутствуют в базе данных PDF2.

Содержание щелочи определяли титрованием водных растворов выщелачивания плавов [13], содержание серы в степенях окисления $\mathrm{S}^{6+}$ и $\mathrm{S}^{2-}$ - осаждением сульфата бария и сульфида меди, соответственно, по методикам, приведенным в $[13,14]$. Общее количество серы в плаве 
устанавливали осаждением сульфата бария из водного раствора после предварительной окислительной обработки гипохлоритом по методике, приведенной в $[9,13]$.

Основанием для обсуждения реальных превращений с участием никелевого концентрата служат результаты рентгенофазового анализа твердых продуктов, полученных в условиях изменения температуры и продолжительности контакта фаз «концентрат - расплав каустической соды». В интервале температур $350-700{ }^{\circ} \mathrm{C}$, когда количество участвующей в реакциях восстановления никеля щелочи составляло 300 \% от массы исходного концентрата и скорости вращения лопастной мешалки 100 об/мин, получали твердые продукты, фазовые составы которых подверглись существенным превращениям. Рентгенограммы представлены на рис. 1-5.

\section{Результаты и обсуждение}

В литературе отсутствуют сведения о свойствах полисульфидных ассоциаций, способных существовать в щелочном плаве в условиях температур $350-700^{\circ} \mathrm{C}$, их растворимости в щелочном плаве, а также влияния последних на свойства плавов, например на их вязкость.

Таким образом, в рамках экспериментальных исследований решались следующие задачи:

- определение влияния температуры и продолжительности контакта сульфидного материала со щелочью на величину расхода реагента в восстановительном процессе;

- определение условий накапливания в щелочном плаве полисульфидных соединений различного состава и их возможное влияние на процесс восстановления никеля из сульфидных соединений.

Из данных табл. 1 (уравнения (2)-(6)) следует, что вероятность диспропорционирования накапливающейся при восстановлении никеля элементной серы с образованием соединений с различной степенью ее окисления высокая. Процессы сопровождаются снижением удельного расхода щелочи в интервале от 2.0 до 1.5 г-моль/г-атом серы. При этом возникают следующие проблемы:

- в щелочных средах термодинамическая стабильность присуща ионам серы в высших степенях окисления $\left(\mathrm{S}^{6+}\right.$ и $\left.\mathrm{S}^{4+}\right)$. Поэтому удержание серы в низших степенях окисления представляется сложной задачей. Подтверждением сказанному могут служить величины стандартных потенциалов окисления серы:

$\varphi_{S O_{3}^{2-} / S O_{4}^{2-}}^{0}=-0,98 \mathrm{~B} ; \quad \varphi_{S_{2} O_{3}^{2-}}^{0} / S O_{4}^{2-}=-0,76 \mathrm{~B} ; \quad \varphi_{S_{2} O_{3}^{2-} / S O_{3}^{2-}}^{0}=-0,58 \mathrm{~B}[15] ;$

- трудности, связанные с определением условий накапливания серосодержащих соединений $\left(\mathrm{S}_{2} \mathrm{O}_{3}{ }^{2-}, \mathrm{SO}_{3}{ }^{2-}\right.$ и др.) в щелочной среде.

Поэтому более предпочтительным представляется присоединение атомов элементной серы к сульфидной. Результаты термодинамических исследований образования полисульфидных соединений натрия свидетельствуют о вероятности их накопления (табл. 2). Как правило, с ростом температуры от 0 до $900{ }^{\circ} \mathrm{C}$ устойчивость ассоциаций снижается.

Термодинамические исследования диспропорционирования элементной серы в щелочной среде с накапливанием полисульфидных соединений свидетельствуют о том, что вероятность протекания реакций ассоциации $\mathrm{S}^{2-}-\mathrm{S}^{0}$ не одинакова и зависит от количества присоединяемых к $\mathrm{S}^{2-}$ атомов элементной серы. Вероятность образования полисульфидов различного состава представляется последовательностью $\mathrm{Na}_{2} \mathrm{~S}_{5}>\mathrm{Na}_{2} \mathrm{~S}_{3}>\mathrm{Na}_{2} \mathrm{~S}_{4}>\mathrm{Na}_{2} \mathrm{~S}_{2}$ (табл. 3).

$$
-336-
$$



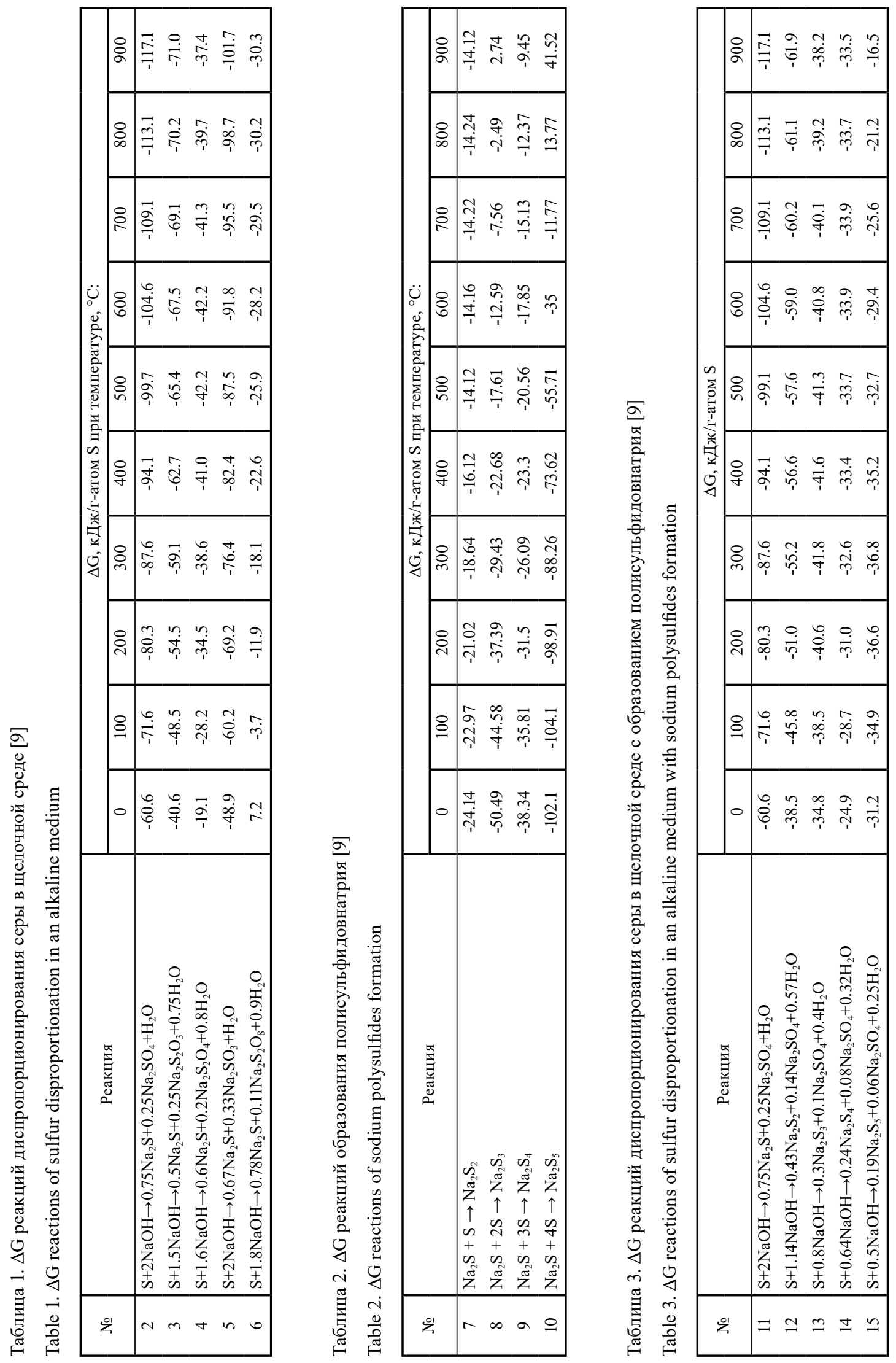
В соответствии с предполагаемым химизмом реакций (11)-(15) имеет место закономерное снижение химического расходования щелочи по мере роста степени ассоциации. При этом величина удельного расхода реагента на 1 г-атом серы снижается с 2 до 0.5 г-моль (с 2.5 до 0.625 г/г) по мере возрастания количества атомов присоединенной к сульфид-иону элементной серы от 0 до 4.

Никельсодержащие соединения, входящие в состав твердых продуктов, представлены металлическим никелем, оксидом $(\mathrm{NiO})$, ферроникелевым сплавом $\left(\mathrm{FeNi}_{3}\right)$ и сульфидом $\left(\mathrm{Ni}_{3} \mathrm{~S}_{2}\right)$. Нами сделано предположение о том, что кислородные соединения никеля, как и ферроникель, являются вторичными продуктами взаимодействия с участием металлического никеля. С учетом данного обстоятельства определяли количество никеля, присутствующего во вновь образующихся материалах.

По результатам рентгенофазового анализа (рис. 1-5) фаза металлического никеля в твердом продукте начинает накапливаться при температуре $450{ }^{\circ} \mathrm{C}$ и содержание металла достигает $14 \%$ через 40 мин контакта фаз. Повышение температуры до $500{ }^{\circ} \mathrm{C}$ приводит к качественному изменению динамики накопления металлического никеля. Так, через 20 мин контакта фаз содержание металлической фазы в твердом продукте достигает 63 \%. Дальнейшее увеличение температуры процесса до $550{ }^{\circ} \mathrm{C}$ обеспечивает получение осадков, содержащих $92 \%$ металлического никеля уже через 12 мин контакта фаз, т. е. приводит к существенному сокращению продолжительности восстановительного процесса. При температуре $700{ }^{\circ} \mathrm{C}$ и продолжительности обработки механической смеси в течение 5 мин содержание металлического никеля достигает $90 \%$. Дальнейшее перемешивание вновь образующихся продуктов сопровождается некоторым снижением содержания фазы металлического никеля, что позволяет предположить протекание обратных процессов сульфидирования металла. Приведенная динамика накапливания в твердом продукте восстановления металлического никеля согласуется с соответствующим уменьшением содержания хизлевудита. Интервал температур $400-500{ }^{\circ} \mathrm{C}$ характеризуется максимальным содержанием в осадке закиси никеля и железоникелевого сплава, достигающим

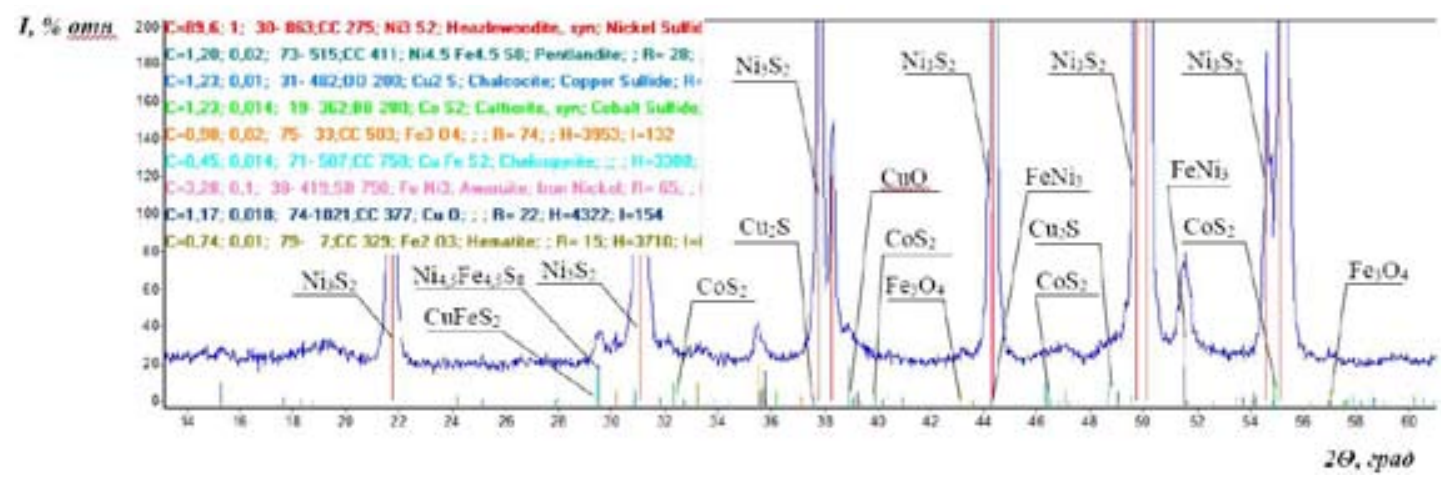

Рис. 1. Фрагмент рентгенограммы кека, полученного при контакте сульфидного никелевого концентрата со щелочью при температуре $350{ }^{\circ} \mathrm{C}$ и продолжительности 40 мин., \%: $\mathrm{Ni}_{3} \mathrm{~S}_{2}-89.6 ; \mathrm{Ni}_{4.5} \mathrm{Fe}_{4.5} \mathrm{~S}_{8}-1.2 ; \mathrm{Cu}_{2} \mathrm{~S}-$ 1.23; $\mathrm{CoS}_{2}-1.23 ; \mathrm{CuFeS}_{2}-0.45 ; \mathrm{Fe}_{3} \mathrm{O}_{4}-0.98 ; \mathrm{FeNi}_{3}-3.28 ; \mathrm{Fe}_{2} \mathrm{O}_{3}-0.74 ; \mathrm{CuO}-1.17$

Fig. 1. X-ray diffraction pattern fragment of the cake obtained by the contact of nickel sulfide concentrate with alkali at a temperature of $350{ }^{\circ} \mathrm{C}$ and duration of 40 minutes, $\mathrm{Ni}_{3} \mathrm{~S}_{2}-89.6 ; \mathrm{Ni}_{4.5} \mathrm{Fe}_{4.5} \mathrm{~S}_{8}-1.2 ; \mathrm{Cu}_{2} \mathrm{~S}-1.23 ; \mathrm{CoS}_{2}-$ 1.23; $\mathrm{CuFeS}_{2}-0.45 ; \mathrm{Fe}_{3} \mathrm{O}_{4}-0.98 ; \mathrm{FeNi}_{3}-3.28 ; \mathrm{Fe}_{2} \mathrm{O}_{3}-0.74 ; \mathrm{CuO}-1.17$ 


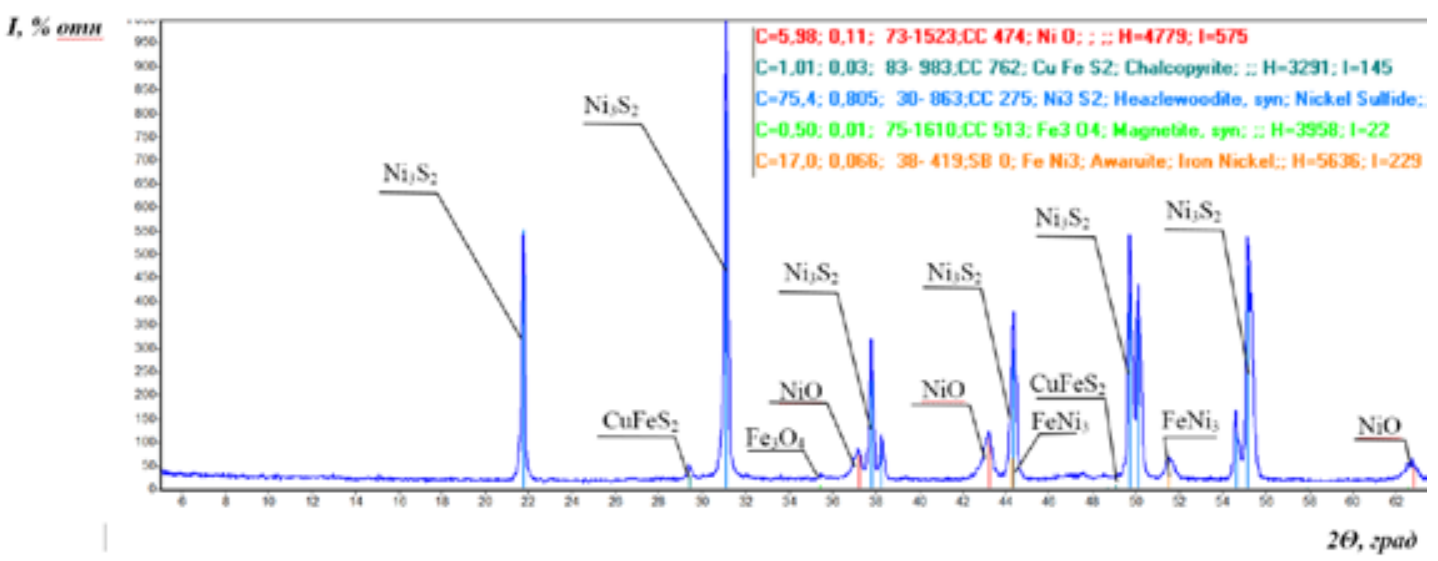

Рис. 2. Фрагмент рентгенограммы кека, полученного при контакте сульфидного никелевого концентрата со щелочью при температуре $400{ }^{\circ} \mathrm{C}$ и продолжительности 40 мин., \%: $\mathrm{Ni}_{3} \mathrm{~S}_{2}-75.4 ; \mathrm{NiO}-5.98 ; \mathrm{CuFeS}_{2}-$ $1.01 ; \mathrm{Fe}_{3} \mathrm{O}_{4}-0.5 ; \mathrm{FeNi}_{3}-17$

Fig. 2. X-ray diffraction pattern fragment of the cake obtained by the contact of nickel sulfide concentrate with alkali at a temperature of $400{ }^{\circ} \mathrm{C}$ and duration of 40 minutes, $\%: \mathrm{Ni}_{3} \mathrm{~S}_{2}-75.4 ; \mathrm{NiO}-5.98 ; \mathrm{CuFeS}_{2}-1.01 ; \mathrm{Fe}_{3} \mathrm{O}_{4}-$ $0.5 ; \mathrm{FeNi}_{3}-17$

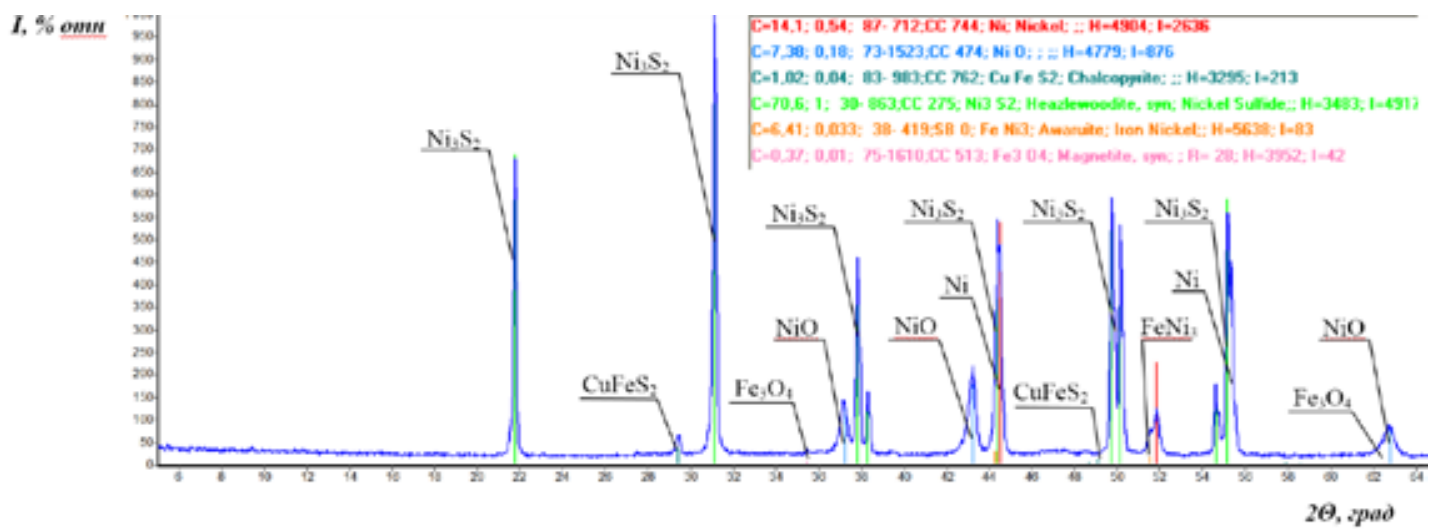

Рис. 3. Фрагмент рентгенограммы кека, полученного при контакте сульфидного никелевого концентрата со щелочью при температуре $450{ }^{\circ} \mathrm{C}$ и продолжительности 40 мин., \%: $\mathrm{Ni}-14.1 ; \mathrm{Ni}_{3} \mathrm{~S}_{2}-70.6 ; \mathrm{NiO}-7.38$; $\mathrm{CuFeS}_{2}-1.02 ; \mathrm{Fe}_{3} \mathrm{O}_{4}-0.37 ; \mathrm{FeNi}_{3}-6.41$

Fig. 3. X-ray diffraction pattern fragment of the cake obtained by the contact of nickel sulfide concentrate with alkali at a temperature of $450{ }^{\circ} \mathrm{C}$ and duration of 40 minutes, \%: $\mathrm{Ni}-14.1 ; \mathrm{Ni}_{3} \mathrm{~S}_{2}-70.6 ; \mathrm{NiO}-7.38 ; \mathrm{CuFeS}_{2}-1.02$; $\mathrm{Fe}_{3} \mathrm{O}_{4}-0.37 ; \mathrm{FeNi}_{3}-6.41$

8 \%. При повышении температуры до $550{ }^{\circ} \mathrm{C}$ содержание указанных продуктов существенно сокращается.

В сложившейся ситуации химизм процесса, сопровождающего восстановление никеля, может быть отслежен с учетом перечисленных далее факторов:

- химических потерь $\mathrm{NaOH}$ (с учетом количества металла, участвующего в превращенияX);

- количества сульфатной серы, накапливаемой в плаве; 


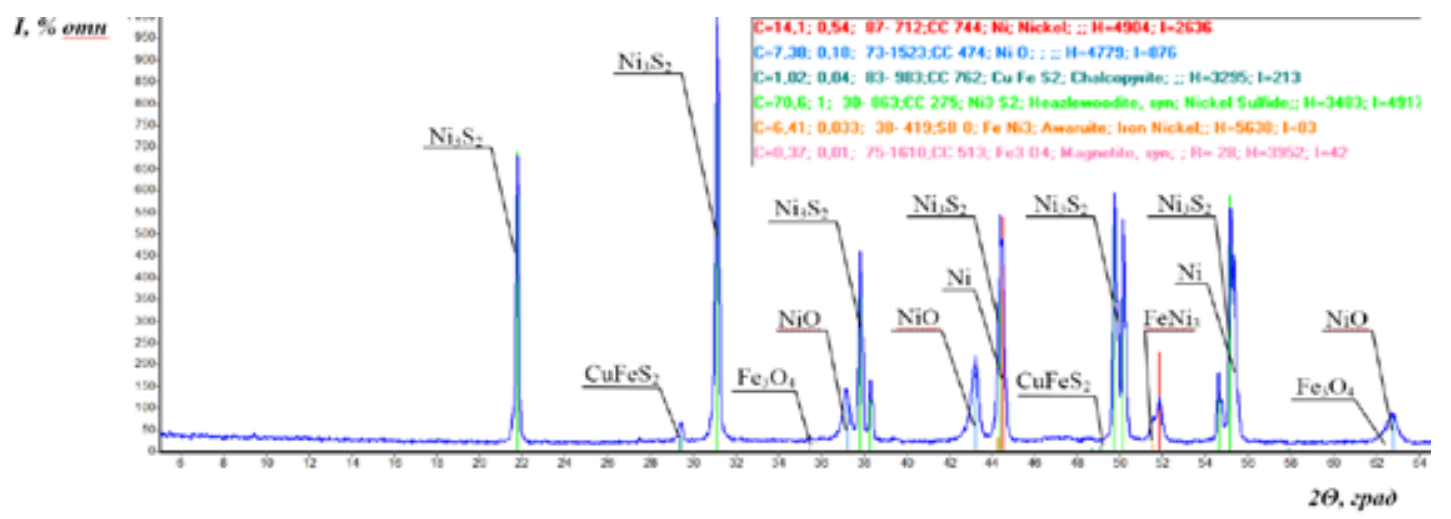

Рис. 4. Фрагмент рентгенограммы кека, полученного при контакте сульфидного никелевого концентрата со щелочью при температуре $500{ }^{\circ} \mathrm{C}$ и продолжительности 20 мин., \%: $\mathrm{Ni}-63.3 ; \mathrm{Ni}_{3} \mathrm{~S}_{2}-27.4 ; \mathrm{NiO}-7.95$; $\mathrm{CuFeS}_{2}-1.31$

Fig. 4. X-ray diffraction pattern fragment of the cake obtained by the contact of nickel sulfide concentrate with alkali at a temperature of $500{ }^{\circ} \mathrm{C}$ and duration of 20 minutes, \%: $\mathrm{Ni}-63.3 ; \mathrm{Ni}_{3} \mathrm{~S}_{2}-27.4 ; \mathrm{NiO}-7.95 ; \mathrm{CuFeS}_{2}-$ 1.31

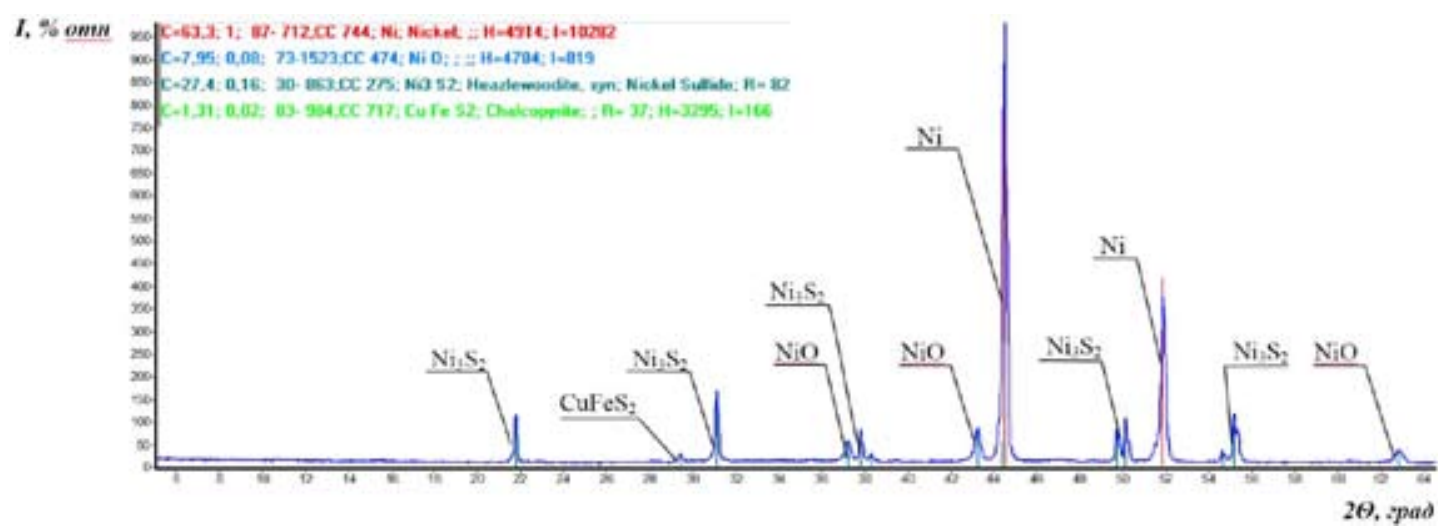

Рис. 5. Фрагмент рентгенограммы кека, полученного при контакте сульфидного никелевого концентрата со щелочью при температуре $550{ }^{\circ} \mathrm{C}$ и продолжительности 12 мин., \%: $\mathrm{Ni}-92.1 ; \mathrm{Ni}_{3} \mathrm{~S}_{2}-2.74 ; \mathrm{NiO}-1.44$; $\mathrm{CuFeS}_{2}-0.89 ; \mathrm{FeNi}_{3}-2.74$

Fig. 5. X-ray diffraction pattern fragment of the cake obtained by the contact of nickel sulfide concentrate with alkali at a temperature of $550{ }^{\circ} \mathrm{C}$ and duration of 12 minutes, $\%$ : $\mathrm{Ni}-92.1 ; \mathrm{Ni}_{3} \mathrm{~S}_{2}-2.74 ; \mathrm{NiO}-1.44 ; \mathrm{CuFeS}_{2}-0.89$; $\mathrm{FeNi}_{3}-2.74$

- выходов твердых продуктов окислительно-восстановительных реакций.

В табл. 4 в соответствии с уравнениями (11)-(15) табл. 3 приведены результаты теоретических расчетов расходования щелочи и накапливания разновалентной серы в плаве, а также удельные показатели расхода $\mathrm{NaOH}$ на единицу массы серы, участвующей в диспропорционированиии на единицу массы восстановленного никеля, а также отношения присутствующей в щелочном плаве общей серы к сере сульфатной.

Из данных табл. 4 следует, что по мере возрастания количества элементной серы, присоединяемой к сульфид-иону (от 0 до 4), закономерно снижается расход $\mathrm{NaOH}$ (примерно в 4 раза), 
участвующей в реакции диспропорционирования, с соответствующим снижением содержания сульфидной (в 4.2 раза) и сульфатной (в 4 раза) серы и возрастанием количества элементной серы в продуктах реакции (на 1 г $\mathrm{S}^{2-}-4$ г $\mathrm{S}^{0}$ ). При этом удельный расход щелочи на 1 г восстановленного никеля снижается в 3.32 раза и, соответственно, отношение количества $\mathrm{NaOH}$ к количеству серы в растворе - в 4 раза.

Проведена экспериментальная проверка высказанного ранее предположения о влиянии на степень полимеризации серы температуры восстановительного процесса [9]. В соответствии с результатами рентгенофазового анализа в табл. 5 приведены составы продуктов, полученных

Таблица 4. Результаты теоретических расчетов расхода реагентов и количеств продуктов реакций при взаимодействии никелевого концентрата со щелочью в условиях образования полисульфидов (n от 0 до 4). В 100 г никелевого концентрата 66,67 г Ni и 24,2 г S

Table 4. The results of theoretical calculations of reagent consumption and the number of reaction products in the interaction of nickel concentrate with alkali in the conditions of polysulfides formation (n from 0 to 4). In $100 \mathrm{~g}$ nickel concentrate $66.67 \mathrm{~g} \mathrm{Ni}$ and $24.2 \mathrm{~g} \mathrm{~S}$

\begin{tabular}{|c|c|c|c|c|c|c|c|c|c|}
\hline № & Расход & \multicolumn{5}{|c|}{ Соли, г } & $\frac{\Sigma \mathrm{S}}{\mathrm{NaOH}}$ & $\frac{\mathrm{NaOH}}{\Sigma}$ \\
\cline { 3 - 6 } реакции & $\mathrm{NaOH,} \mathrm{г}$ & $\mathrm{Na}_{2} \mathrm{~S} \cdot \mathrm{S}_{\mathrm{i}}$ & $\mathrm{S}^{2-}$ & $\mathrm{S}^{0}$ & $\mathrm{Na}_{2} \mathrm{SO}_{4}$ & $\mathrm{~S}^{6+}$ & $\mathrm{S}^{6+}$ & $\mathrm{Ni}$ & $\Sigma \mathrm{S}$ \\
\hline 11 & 62.5 & 45.7 & 19.32 & & 27.8 & 6.26 & 4 & 0.93 & 2.5 \\
12 & 35.74 & 36.86 & 10.7 & 10.7 & 15.8 & 3.56 & 7.02 & 0.53 & 1.43 \\
13 & 25 & 33.3 & 7.5 & 15 & 11.06 & 2.49 & 10.04 & 0.37 & 1.0 \\
14 & 19.2 & 31.4 & 5.77 & 17.31 & 8.53 & 1.92 & 13.02 & 0.28 & 0.77 \\
15 & 15.64 & 30.2 & 4.6 & 18.4 & 6.95 & 1.57 & 15.92 & 0.23 & 0.62 \\
\hline
\end{tabular}

Таблица 5. Фазовый состав продуктов восстановления никеля (40 г НКРФ, содержащего 26.67 г Ni и 9.69 г S) Table 5. The phase composition of the nickel reduction products ( $40 \mathrm{~g}$ NCCMS containing $26.67 \mathrm{~g} \mathrm{Ni}$ and $9.69 \mathrm{~g} \mathrm{~S}$ )

\begin{tabular}{|c|c|c|c|c|c|c|c|c|c|c|c|c|c|}
\hline \multirow{3}{*}{ T. ${ }^{\circ} \mathrm{C}$} & \multirow{3}{*}{$\tau$. мин } & \multicolumn{12}{|c|}{ Содержание в твердой фазе } \\
\hline & & \multicolumn{2}{|c|}{$\mathrm{Ni}$} & \multicolumn{3}{|c|}{$\mathrm{NiO}$} & \multicolumn{3}{|c|}{$\mathrm{FeNi}_{3}$} & \multicolumn{4}{|c|}{$\mathrm{Ni}_{3} \mathrm{~S}_{2}$} \\
\hline & & $\%$ & $\Gamma$ & $\%$ & $\Gamma$ & $\Gamma^{*}$ & $\%$ & $\Gamma$ & $\Gamma^{*}$ & $\%$ & $\Gamma$ & $\Gamma^{*}$ & $\Gamma^{* *}$ \\
\hline 350 & 40 & & & & & & 3.28 & 1.21 & 0.93 & 89.6 & 33.2 & 24.3 & 8.89 \\
\hline \multirow{2}{*}{400} & 40 & & & 5.98 & 2.16 & 1.7 & 17 & 6.12 & 4.64 & 75.4 & 27.1 & 19.9 & 7.22 \\
\hline & 60 & 0.67 & 0.23 & 7.38 & 2.59 & 2.03 & 10.9 & 3.81 & 2.89 & 79.6 & 27.9 & 20.5 & 7.4 \\
\hline \multirow{3}{*}{450} & 20 & 13.7 & 5.01 & 4.52 & 1.65 & 1.3 & 4.05 & 1.7 & 1.3 & 74.4 & 27.2 & 20 & 7.25 \\
\hline & 60 & 28.2 & 9.73 & 7.53 & 2.6 & 2.04 & 6.93 & 2.39 & 1.81 & 55.7 & 19.2 & 14.1 & 5.11 \\
\hline & 150 & 48.1 & 15.7 & 6.79 & 2.2 & 1.73 & 5.72 & 1.86 & 1.41 & 37.2 & 12.2 & 8.89 & 3.23 \\
\hline \multirow{2}{*}{500} & 20 & 63.3 & 19.6 & 7.95 & 2.46 & 1.93 & & & & 27.4 & 8.43 & 6.23 & 2.26 \\
\hline & 30 & 85.8 & 25 & 4.04 & 1.18 & 0.93 & & & & 6.96 & 2.04 & 1.5 & 0.54 \\
\hline \multirow{2}{*}{550} & 10 & 84.8 & 24.6 & 1.37 & 0.38 & 0.3 & 8.37 & 2.43 & 1.84 & 2.88 & 0.67 & 0.49 & 0.18 \\
\hline & 20 & 94.3 & 26.12 & 1.48 & 0.41 & 0.32 & & & & 2.43 & 0.67 & 0.49 & 0.18 \\
\hline \multirow{3}{*}{650} & 5 & 90.4 & 25.3 & 1.22 & 0.37 & 0.29 & 2.96 & 0.83 & 0.63 & 1.71 & 0.47 & 0.34 & 0.12 \\
\hline & 10 & 88.8 & 25.45 & 2.0 & 0.57 & 0.45 & 2.9 & 0.83 & 0.63 & 2.4 & 0.69 & 0.46 & 0.17 \\
\hline & 15 & 89.8 & 26.1 & 2.63 & 0.75 & 0.6 & 2.94 & 0.84 & 0.64 & 0.97 & 0.28 & 0.21 & 0.075 \\
\hline \multirow{2}{*}{700} & 5 & 87.7 & 25.7 & 4.71 & 1.38 & 1.09 & 1.24 & 0.36 & 0.27 & 2.44 & 0.11 & 0.52 & 0.19 \\
\hline & 10 & 94.2 & 26.3 & - & - & - & 2.89 & 0.81 & 0.61 & - & - & - & - \\
\hline
\end{tabular}

Примечание: $\Gamma^{*}$ - масса никеля в соединении, $\Gamma^{* *}-$ масса серы в соединении. 
Таблица 6. Экспериментальные данные об изменениях вещественного состава нерастворимой и солевой составляющих щелочного плава (40 г НКРФ, содержащего 26.67 г Ni и 9.69 г S)

Table 6. Experimental data on changes in the material composition of insoluble and salt components of the alkaline melt (40 g NCCMS containing $26.67 \mathrm{~g}$ Ni and $9.69 \mathrm{~g} \mathrm{~S}$ )

\begin{tabular}{|c|c|c|c|c|c|c|c|c|c|}
\hline $\mathrm{T},{ }^{\circ} \mathrm{C}$ & $\tau$, мин & $\mathrm{m}_{\text {н.o. }}, \Gamma$ & $\Delta \mathrm{NaOH}, \Gamma$ & $\Sigma \mathrm{Ni}, \Gamma$ & $\mathrm{S}_{\mathrm{p}}, \Gamma$ & $\frac{\Delta \mathrm{NaOH}}{\Sigma \mathrm{Ni}}$ & $\frac{\Delta \mathrm{NaOH}}{\mathrm{S}_{\mathrm{p}}}$ & $\mathrm{S}^{6+}, \Gamma$ & $\begin{array}{l}\underline{S}_{p} \\
S^{6+}\end{array}$ \\
\hline 350 & 40 & 37 & 0.28 & 0.93 & 0.42 & 0.29 & 0.64 & 0.05 & 13.1 \\
\hline \multirow{2}{*}{400} & 40 & 36 & 1.5 & 4.64 & 2.14 & 0.32 & 0.7 & 0.16 & 13.2 \\
\hline & 60 & 35 & 1.65 & 5.51 & 2.35 & 0.32 & 0.7 & 0.18 & 13.1 \\
\hline \multirow{3}{*}{450} & 20 & 36.6 & 2.3 & 7.6 & 2.92 & 0.32 & 0.78 & 0.24 & 12.3 \\
\hline & 60 & 34.5 & 4 & 13.6 & 4.78 & 0.31 & 0.88 & 0.38 & 12.5 \\
\hline & 150 & 32.6 & 5.4 & 18.8 & 6.45 & 0.29 & 0.85 & 0.5 & 12.9 \\
\hline \multirow{2}{*}{500} & 20 & 31 & 7.75 & 21.5 & 7.63 & 0.36 & 1.02 & 0.74 & 10.3 \\
\hline & 30 & 29.1 & 9.6 & 25.93 & 9.25 & 0.37 & 1.04 & 0.9 & 10.3 \\
\hline \multirow{2}{*}{550} & 10 & 29 & 9.9 & 26.74 & 9.81 & 0.47 & 1.17 & 1.08 & 9.08 \\
\hline & 20 & 27.7 & 9.7 & 26.41 & 9.9 & 0.42 & 1.14 & 1.05 & 9.43 \\
\hline \multirow{3}{*}{650} & 5 & 27.8 & 17.8 & 26.2 & 9.45 & 0.71 & 1.88 & 1.85 & 5.1 \\
\hline & 10 & 28.5 & 18.5 & 26.5 & 9.6 & 0.7 & 1.95 & 1.82 & 5.21 \\
\hline & 15 & 29 & 20 & 26.67 & 9.65 & 0.75 & 2.07 & 1.93 & 5.0 \\
\hline \multirow{2}{*}{700} & 5 & 29.3 & 24 & 26.15 & 9.66 & 0.918 & 2.48 & 2.34 & 4.13 \\
\hline & 10 & 27.9 & 24.2 & 26.67 & 9.73 & 0.91 & 2.49 & 2.4 & 4.05 \\
\hline
\end{tabular}

после термообработки системы в интервале температур $350-700{ }^{\circ} \mathrm{C}$ при соответствующей продолжительности контакта. В целом, при температуре $550{ }^{\circ} \mathrm{C}$ имеет место последовательное возрастание содержания металлического никеля в продукте при соответствующем снижении содержания закиси никеля и незакономерном накапливании сплава ферроникеля. Указанное согласуется с соответствующим снижением содержания в продукте хизлевудита.

В табл. 6 приведены массы нерастворимых осадков $\left(\mathrm{m}_{\text {н.о }}\right.$, г), образующихся в результате окислительно-восстановительных взаимодействий с участием сульфидов никелевого концентрата, количества химически израсходованной щелочи $(\Delta \mathrm{NaOH}, r)$, а также количества никеля, участвующего в превращениях $(\Sigma \mathrm{Ni}$, г), количества общей и сульфатной серы, накапливаемой в щелочном плаве $\left(\mathrm{S}_{\mathrm{p}}\right.$ и $\left.\mathrm{S}^{6+}\right)$.

Полученные экспериментальные данные позволили определить в каждой серии опытов величины удельных расходов щелочи, отнесенные к единице массы общей серы, накапливающейся в плаве $\left(\Delta \mathrm{NaOH} / \mathrm{S}_{\mathrm{p}}\right)$, и к единице массы никеля, участвующего в преобразовании $(\Delta \mathrm{NaOH} / \Sigma \mathrm{Ni})$, а также установить среднее количество серы, отнесенное к количеству серы сульфатной, дающее возможность определить количество элементной серы в полисульфиде.

В температурном интервале $350-700{ }^{\circ} \mathrm{C}$ удельный расход $\mathrm{NaOH}$ на единицу массы никеля изменяется от 0.29 до 0.91 г/г. Величина отношения $\Delta \mathrm{NaOH} / \mathrm{S}_{\mathrm{p}}$ также возрастает от 0.64 до 2.48 , что не выходит за рамки теоретических расчетов (табл. 4). Удельный расход щелочи, отнесенный к количеству общей серы в плаве, в зависимости от температуры, аналогичен приведенному для восстановления никеля.

Химические потери щелочи при осуществлении окислительно-восстановительных реакций с участием сульфидов никеля предположительно обусловлены образованием полисуль- 


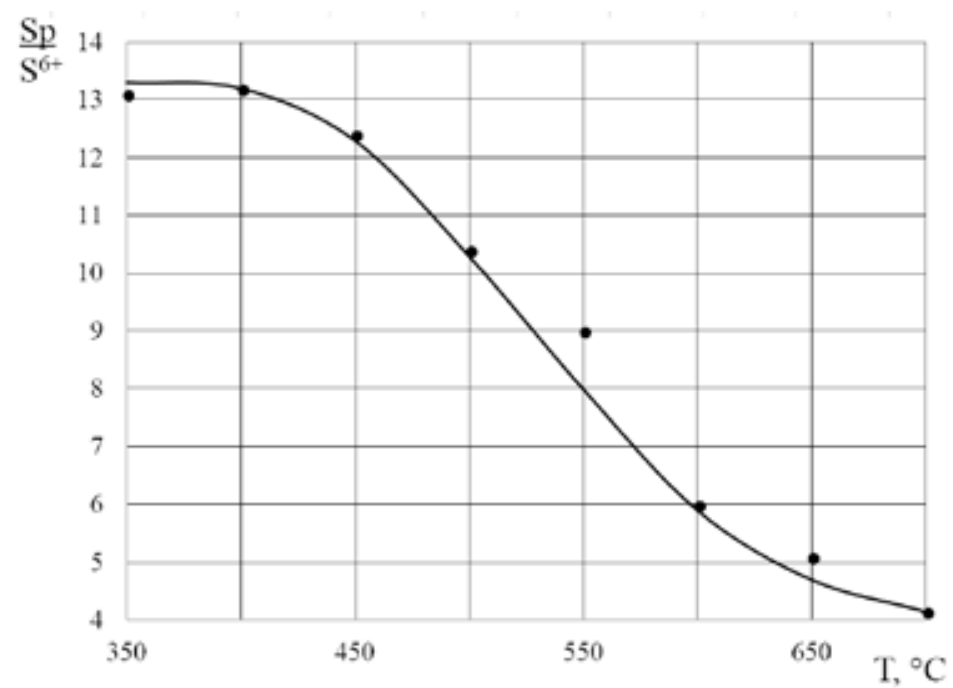

Рис. 6. Зависимость содержания серы в полисульфиде от температуры

Fig. 6. Temperature dependence of sulfur content in polysulfide

фидных соединений, в которых в качестве центра ассоциации выступает сульфид-ион, присоединяющий к себе некоторое количество атомов элементной серы. Это вполне устойчивые соединения, но их существование определяется температурой системы, в которой они формируются.

На основании исследований химизма ассимиляции серы в щелочном плаве пришли к выводу, что количество сульфатной серы, накапливающейся в плаве, является количественным показателем степени полимеризации. Чем больше атомов серы присоединяется к сульфидиону, тем меньше содержание $\mathrm{S}^{6+}$ в плаве. За количественный определитель ассоциированных частиц серы было взято отношение общей серы в плаве к количеству сульфатной серы. На рис. 6 приведена зависимость данного отношения от температуры, из которой следует, что по мере увеличения температуры системы с 350 до $700{ }^{\circ} \mathrm{C}$ наблюдается закономерное снижение степени ассоциации. В интервале температур $350-450{ }^{\circ} \mathrm{C}$ в щелочном плаве накапливается преимущественно $\mathrm{Na}_{2} \mathrm{~S}_{4}$. В условиях температур 500-550 ${ }^{\circ} \mathrm{C}$ в плаве присутствуют соединения $\mathrm{Na}_{2} \mathrm{~S}_{3}\left(500^{\circ} \mathrm{C}\right)$, а также полисульфидные смеси $\mathrm{Na}_{2} \mathrm{~S}_{3}$ и $\mathrm{Na}_{2} \mathrm{~S}_{2}$ с преимущественной концентрацией $\mathrm{Na}_{2} \mathrm{~S}_{3}$. В области температуры $650{ }^{\circ} \mathrm{C}$ в плаве сосуществуют $\mathrm{Na}_{2} \mathrm{~S}_{2}$ и $\mathrm{Na}_{2} \mathrm{~S}$ с преимущественным содержанием $\mathrm{Na}_{2} \mathrm{~S}$. Для температуры $700{ }^{\circ} \mathrm{C}$ характерно существование в щелочном плаве моносульфида. Такое представление о серопродуктах, накапливаемых в щелочном плаве, не противоречит экспериментальным данным о химических потерях гидроксида натрия.

С учетом приведенных выше сведений об изменяющемся составе продуктов диспропорционирования элементной серы в зависимости от температуры вид динамических кривых восстановления никеля из сульфидов изображен на рис. 7, из которого следует, что скорость процесса металлизации никеля, по-видимому, зависит от степени полимеризации сульфидного компонента в плаве. Рост количества атомов серы, присоединяемых к сульфид-иону, снижает скорость восстановления никеля, что подтверждается характером динамических кривых, полученных для температур 400, 450, 500 и $550{ }^{\circ} \mathrm{C}$, когда в щелочном плаве присутствуют 


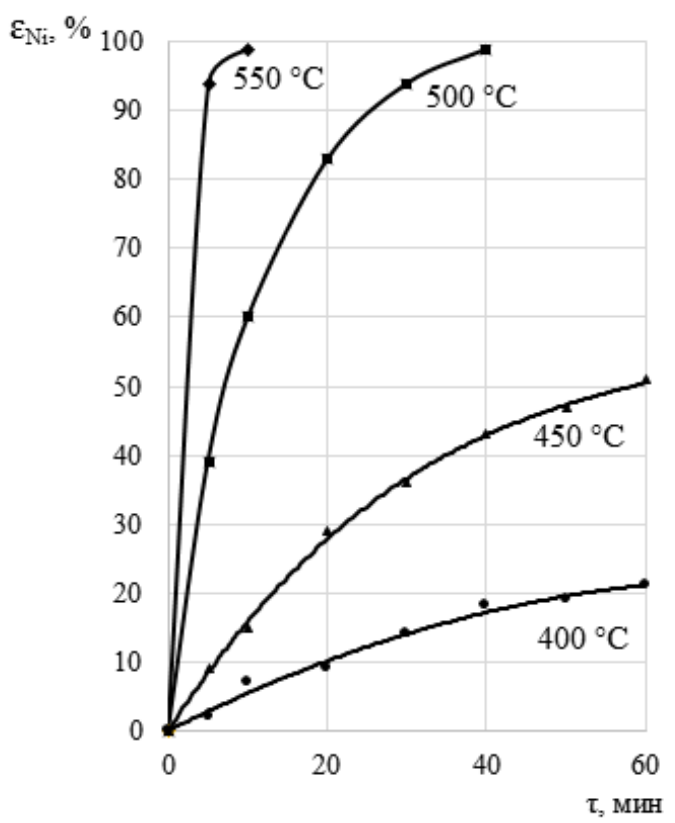

Рис. 7. Зависимости степени восстановления никеля из сульфида от продолжительности контакта фаз

Fig. 7. Dependence of the nickel reduction degree from nickel sulfide and duration of phases contact

соединения $\mathrm{Na}_{2} \mathrm{~S}_{4}, \mathrm{Na}_{2} \mathrm{~S}_{3}$ и $\mathrm{Na}_{2} \mathrm{~S}_{2}$, в том числе в различных концентрационных соотношениях. Соответственно, скорость процесса существенно возрастает по мере уменьшения количества присоединенных к сульфид-иону атомов элементной серы.

С повышением температуры с 400 до $450{ }^{\circ} \mathrm{C}$ скорость восстановления увеличивается примерно в 3 раза, с 400 до $500{ }^{\circ} \mathrm{C}$ - в 16 раз, с 400 до $550{ }^{\circ} \mathrm{C}$ - в 20 раз. Скорость восстановления никеля с накапливанием моносульфида еще более значительна. При температуре $550{ }^{\circ} \mathrm{C}$ обеспечивается глубокое восстановление никеля через 10-15 мин перемешивания фаз. При температуре $500^{\circ} \mathrm{C}$ аналогичное превращение завершается через 50-55 мин.

\section{Заключение}

1. Одним из путей снижения химических потерь $\mathrm{NaOH}$ является реализация диспропорционирования с накапливанием полисульфидных соединений $\mathrm{Na}_{2} \mathrm{~S} \cdot \mathrm{S}_{\mathrm{n}}$, которое может быть реализовано в условиях пониженных температур восстановительного процесса $\left(500-550{ }^{\circ} \mathrm{C}\right)$. Ведение восстановления при $550^{\circ} \mathrm{C}$ обеспечивает накапливание в щелочном плаве соединений $\mathrm{Na}_{2} \mathrm{~S}_{3}$ и, соответственно, снижение химических потерь щелочи в 2.0-2.5 раза.

2. Определены температурные диапазоны существования полисульфидов натрия в щелочном плаве для интервала температур $350-700{ }^{\circ} \mathrm{C}$. Установлено влияние степени полимеризации на кинетику восстановления никеля непосредственно из сульфидных соединений. 


\section{Список литературы}

1. Резник И.Д., Ермаков Г.П., Шнеерсон Я.М. Никель: В 3 т. Т. 3. М.: ООО «Наука и технологии», 2003. 608 c. [Reznik I.D., Ermakov G.P., Shneerson Ya.M. Nickel: In 3 volumes. Vol. 3. Moskow, Nauka i tehnologii, 2003. 608 p. (In Russ.)]

2. Чекушин В.С., Олейникова Н.В. Термодинамика восстановления никеля и кобальта из кислородных и сульфидных соединений. Журнал Сибирского федерального университета. Техника и технология 2008, T. 1(1), C. 58-67. [Chekushin V.S., Oleynikova N.V. Thermodinamics of reduction of nickeland cobalt from oxide and sulfide compounds. Journal of Siberian Federal University. Engineering and Technologies 2008. Vol. 1 (1), P. 58-67. (In Russ.)]

3. Чекушин В.С., Олейникова Н.В., Донцов А.В., Дубинин П.С. Восстановительные процессы в системе никелевый концентрат разделения файнштейна - каустическая сода. Технология металлов 2008. № 10, C. 2-7. [Chekushin V.S., Oleynikova N.V., Dontsov A.V., Dubinin P.S. Reduction processes in the system nickel concentrate of converter matte separation - caustic soda. Technology of metals 2008. Vol. 10, P. 2-7. (In Russ.)]

4. Chekushin V.S., Oleinikova N.V., Dontsov A.V. Reduction of nickel from sulfides of the concentrate of the bessemer matte separation. Russian Journal of Non-Ferrous Metals 2010. Vol. 51(1), P. $32-38$

5. Наумов Г.Б., Рыженко Б.Н., Ходаковский И.Л. Справочник термодинамических величин (для геологов). М.: Атомиздат, 1971. 237 с. [Naumov G.B., Ryzhenko B.N. Khodokovskiy I.L. Handbook of thermodynamic quantities (for geologists). Moskow: Atomizdat, 1971. 237 p. (In Russ.)]

6. Карапетьянц М.Х., Карапетьянц М.Л. Основные термодинамические константы неорганических и органических веществ. М.: Химия, 1968. 470 c. [Karapetyants M.Kh., Karapetyants M.L. Basic thermodynamic constants of inorganic and organic substances. Moskow: Chimiya, 1968. $470 \mathrm{p}$. (In Russ.)]

7. Мищенко К.П., Равдель А.А. Краткий справочник физико-химических величин. Л.: Химия, 1974. 340 c. [Mishchenko K.P., Ravdel A.A. Short handbook of physico-chemical quantities. Leningrad: Chimiya. 1974. 340p. (In Russ.)]

8. Справочник химика: в 5 т. Т. 1. Под общ. ред. Б.П. Никольского. Л.-М.: ГХИ, 1963. 987 с. [Chemist's Handbook: In 5 volumes. Vol. 5. Under Ed. Nikolskogo B.P. Leningrad, Moskow: GKhI. 1963. 987 p. (In Russ.)]

9. Чекушин В.С., Олейникова Н.В. Щелочная плавка в процессах восстановления и экстракции тяжельх иветных металлов. Красноярск: ООО «Поликом», 2011. 332 с. [Chekushin V.S., Oleynikova N.V. The alkaline smelt in reduction and extraction processes of heavy non-ferrous metals. Krasnoyarsk: Polikom, 2011. 332 p. (In Russ.)]

10. Якимов И.С. Система рентгенофазовой идентификации существенно многофазных материалов. Заводская лаборатория. Диагностика материалов 2007. Т. 73(11), С. 32-37. [Yakimov I.S. System x-ray phase identification of the substantially multi-phase materials. Industrial laboratory. Diagnostics of materials 2007. Vol. 73(11), P. 32-37. (In Russ.)]

11. Якимов И.С., Дубинин П.С., Пиксина О.Е. Регуляризированный мультирефлексный метод ссылочных интенсивностей для количественного рентгенофазового анализа поликристаллических материалов. Заводская лаборатория. Диагностика материалов 2010. Т. 76(12), C. 21-26. [Yakimov I.S., Dubinin P.S., Piksina O.E. Regularized multireflex reference intensity method

$$
-345-
$$


for quantitative x-ray phase analysis of polycrystalline materials materials. Industrial laboratory. Diagnostics of materials. 2010. Vol. 76(12), P. 21-26. (In Russ.)]

12. Якимов И.С., Бурова Е.М., Щедрин Б.М. Информационно-поисковая система рентгенофазного анализа. ХІ Всесоюзное совещание рентгенографии минерального сырья. Тезисы докл. Миасс, 1989. Т. 1, С. 66. [Yakimov I.S., Burova E.M., Shchedrin B.M. Information retrieval system of X-ray analysis. XI All-Union conference roentgenography of mineral raw materials. Miass, 1989. Vol. 1, P. 66. (In Russ.)]

13. Суворовская Н.А., Титов В.И., Бродская В.М и др. Технический анализ в иветной металлургии. М.: Металлургиздат, 1957. 567 с. [Suvorovskaya N.A. et. al. Technical analysis in nonferrous metallurgy. Moskow: Metallurgizdat, 1957. 567 p. (In Russ.)]

14 Шарло Г. Методы аналитической химии. В 2-х ч. Ч. 2. М.: Химия, 1969. 976 с. [Sharlo G. Analytical chemistry methods. In 2 parts. Parts 2. Moskow: Chimiya, 1969. 976 p. (In Russ.)]

15. Дей К., Селбин Д. Теоретическая неорганическая химия. М.: Химия, 1969. 432 с. [Dei К., Selbin D. Theoretical inorganic chemistry. Moscow: Khimiya, 1969. 432 p. (in Russ.)] 